\title{
Experimental Setup for Ultrasonic-Assisted Desktop Fused Deposition Modeling System
}

\author{
Maidin, S. ${ }^{1, a}$, Muhamad, M.K. ${ }^{2, b}$ and E. Pei ${ }^{3, c}$ \\ ${ }^{1,2}$ Faculty of Manufacturing Engineering, Universiti Teknikal Malaysia Melaka, Hang Tuah Jaya, \\ 76100 Durian Tunggal, Melaka, Malaysia
}

${ }^{3}$ Faculty of Art, Design and Humanities, De Montfort University, Leicester LE1 9BH, UK

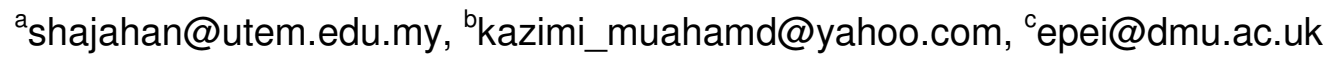

Keywords: Fused Deposition Modeling, Ultrasound, Experimental Setup

Abstract. Fused deposition modeling (FDM) is an additive manufacturing (AM) process that has been used in various manufacturing fields. However, the drawback of FDM is poor surface finish of part produced, leading to surface roughness and requires hand finishing. In this study, ultrasonic technology will be integrated into a desktop FDM system. Ultrasound has been applied in various conventional machining process and shows good machined surface finish. However, very little research regarding the application of ultrasound to AM has been carried out. Our previous research found that the extrusion nozzle of the FDM system could withstand the high vibration transmitted at $40 \mathrm{kHz}$ of frequency from an ultrasonic transducer. The aim of this paper is to discusses three novel setups of using ultrasound devices attached to a desktop FDM system to study its feasibility to improve the surface finish of parts produced. A comparative study was made and it was found that the second setup (Concept 2) was most suitable due to its safe and reliability aspects.

\section{Introduction}

AM has seen rapid uptake over the last decade in the industry. As it becomes more widely available, FDM systems that use a wide range of materials in a filament form has shown to be increasingly popular due to its availability and cost effectiveness [1,2]. Various applications can be produced through the use of FDM such as design verification, functional testing, and design studies[3]. Despite its ability to build functional parts with complex geometrical shapes, the final result of FDM parts usually requires some form of post-processing such as hand finishing.

The purpose of this research is to investigate the novel use of an ultrasonic-assisted technique to improve the surface quality of parts built by FDM. Ultrasound is a proven technology that has been extensively used for machining and it has been claimed to improve surface quality of work pieces [4]. The ultrasonic vibration with piezoelectric components that vibrate in a vertical direction have been used to assist laser machining and it has produced results with a better surface finish [5].

In the FDM process, the material is melted and extruded via a heated nozzle by form each layer to generated sections of parts [6].The main disadvantage of the FDM process is that seam lines appear between layers and excess material may sometimes be produced as a residue, leading to surface roughness and poor finish [7]. Researchers have proposed that better surface finish for AM parts could be achieved by having an (i) optimal build orientation (ii) slicing strategy (iii) optimising the built parameters, and (iv) post-processing. More specifically for the 
FDM process, good surface can be obtained by considering the required layer thickness, the cross-sectional shape and the built surface angle required [8]. The use of chemical treatment for FDM parts has shown potential but at the expense of a negligible change in the volume and may also affect the structural integrity of the prototype [7]. In addition, this technique requires time, set up and costly.

\section{Methodology}

Fig. 1 shows the FDM UP Plus 2 3D printer which has build size of 140mm X 140mm $\mathrm{X} 135 \mathrm{~mm}$ and a $0.4 \mathrm{~mm}$ nozzle diameter was used due to its ability to achieve fine build parameter through its thin layer thickness and road width, as well as being compatible with the ultrasonic-assisted system. The printer was chosen due to its popularity among users, as well as it availability. The material that will be used in this research is ABS plastic which is the most common material for FDM systems. To aid the investigation, a standard piezoelectric ultrasonic transducer operating in a vertical vibration mode will be designed, fabricated and securely mounted onto the nozzle of FDM machine. A power generator with a maximum power of $100 \mathrm{~W}$ having an adjustable frequency ranging 17 to $23 \mathrm{kHz}$ will be used to power the device. During experiment, the frequency will be set at $20 \mathrm{kHz}$, following which the generated oscillation by the transducer is then transferred, amplified, and focused to the tip of the FDM nozzle as shown in (Fig. 2).

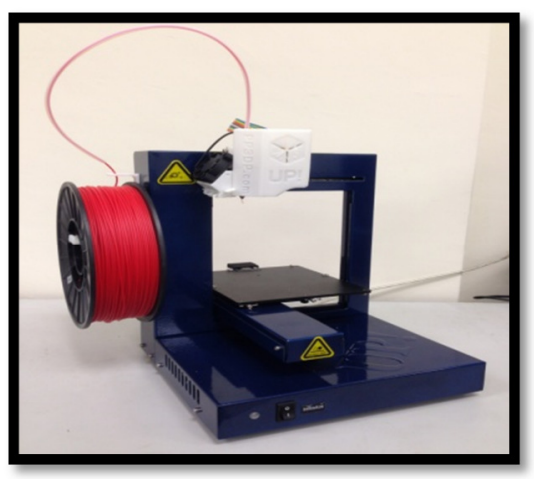

Fig.1: UP Plus 2 3D printer.

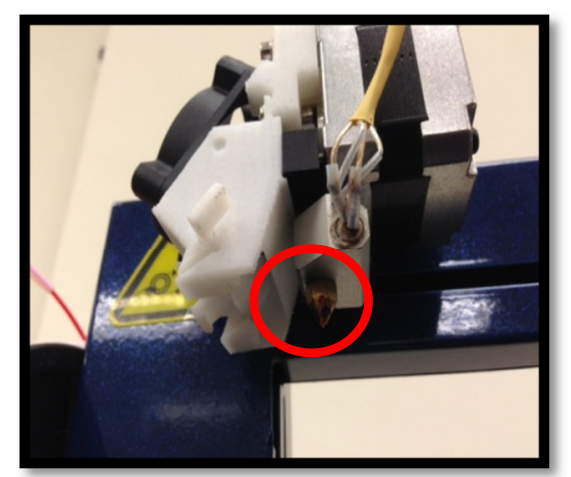

Fig.2: The nozzle of FDM

Piezoelectric transducers used for ultrasonic assisted machining (UAM) generate mechanical motion through the piezoelectric effect through the use of certain materials, such as quartz or lead zirconate titanate. In contrast, magnetostrictive transducers are usually constructed from a laminated stack of nickel or nickel alloy sheets. The exact vibration frequency yielding an axial vibration mode will be calculated using the FEM Nastran-Patran software package and the vibration control from the prototype will be measured using a vibrometer controller.

In this research, the ultrasonic generator which was custom-made had a maximum power of $100 \mathrm{~W}$ with $20 \mathrm{kHz}$ frequency. The amplitude of no-load vibration of the actuator was $10 \mu \mathrm{m}$, however it was not measured under load. To amplify the generated vibration, the transducer had to be stimulated around its natural frequency. The natural frequency of the actuator will be measured using a simple experiment setup as shown in Fig. 3. 


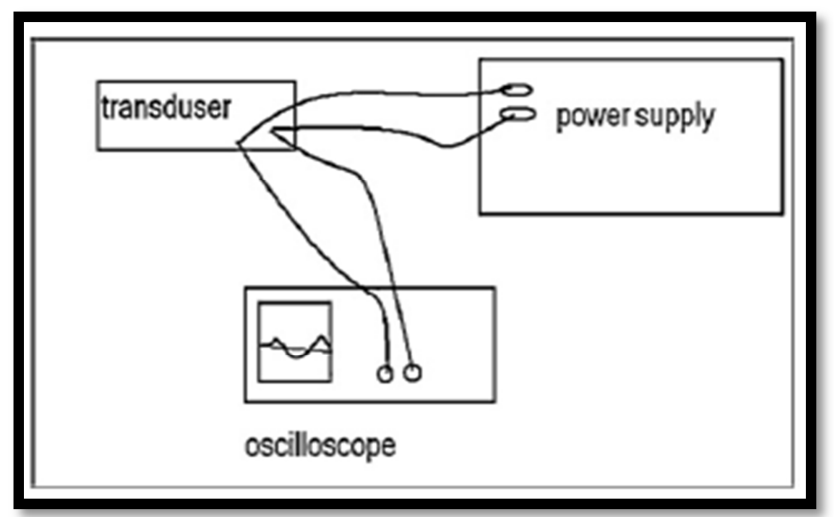

Fig.3: Schematic diagram of ultrasonic transducer

From our previous research, the nozzle of FDM system can stand with maximum 40 $\mathrm{kHz}$ frequency with a factor of safety (FoS) of 18.8975 [9]. The previous study also proved that the screws that hold the extrusion nozzle tips do not become loose when the vibration is applied due to the high frequency vibration applied to the nozzle. For this research, three experimental setups were developed to explain how the ultrasonic vibration will be connected to the FDM desktop system. Table 1 shows three novel experimental setups for the ultrasonic-assisted FDM system.

Table 1: Ultrasonic-Assisted FDM System Experimental Setup

\begin{tabular}{|c|c|c|c|}
\hline Conceptual & Concept 1 & Concept 2 & Concept 3 \\
\hline & orkp pee & Cork piece & Workpiece \\
\hline $\begin{array}{l}\text { Description of } \\
\text { experiment setup }\end{array}$ & $\begin{array}{l}\text { In the first concept, the } \\
\text { transducer will be } \\
\text { attached to the body of } \\
\text { nozzle. }\end{array}$ & $\begin{array}{l}\text { The Second concept uses } \\
\text { a sheet metal as a support } \\
\text { on the transducer placed } \\
\text { on the exterior of nozzle. }\end{array}$ & $\begin{array}{l}\text { The last concept } \\
\text { suggests that the work } \\
\text { piece is clamped on the } \\
\text { surface of ultrasonic } \\
\text { transducer. }\end{array}$ \\
\hline Installation & $\begin{array}{l}\text { The transducer will be } \\
\text { attached parallel on the } \\
\text { top of heater block. The } \\
\text { transducer vibration } \\
\text { transmitted from the top } \\
\text { of heater block to the } \\
\text { nozzle. }\end{array}$ & $\begin{array}{l}\text { Sheet metal is used to } \\
\text { hold the transducer that is } \\
\text { pivoted on the nozzle } \\
\text { being welded or screwed }\end{array}$ & $\begin{array}{l}\text { The transducer is } \\
\text { clamped on the side of } \\
\text { work piece. Only the } \\
\text { work piece will be } \\
\text { vibrated by transducer. }\end{array}$ \\
\hline Safety & $\begin{array}{l}\text { The transducer should be } \\
\text { monitored regularly and } \\
\text { be in a safe temperature as } \\
\text { the heater block has a high } \\
\text { temperatures and can } \\
\text { damage the transducer. }\end{array}$ & $\begin{array}{l}\text { The selection of material } \\
\text { for sheet metal need to be } \\
\text { considered because of } \\
\text { transducer's temperature is } \\
\text { too high and exterior } \\
\text { transducer become easier } \\
\text { to monitor. }\end{array}$ & $\begin{array}{l}\text { The work piece will } \\
\text { need to be properly } \\
\text { aligned to the origin } \\
\text { due to increased weight } \\
\text { and for it to move up } \\
\text { and down on the build } \\
\text { plate smoothly. }\end{array}$ \\
\hline
\end{tabular}




\begin{tabular}{|l|l|l|l|}
\hline Reliability & $\begin{array}{l}\text { The transducer mounted } \\
\text { on the top surface of the } \\
\text { heater box without } \\
\text { disturbing the process of } \\
\text { melting the filament } \\
\text { directly into nozzle. }\end{array}$ & $\begin{array}{l}\text { directly connected to } \\
\text { nozzle. }\end{array}$ & $\begin{array}{l}\text { Fear of instability on } \\
\text { the model produced } \\
\text { due to the vibration of } \\
\text { work piece. }\end{array}$ \\
\hline
\end{tabular}

\section{Evaluation Parameter}

In the proposed methodology, the parameter that will we evaluated later include the feed rate, road width and layer thickness were chosen as factors that would identify the quality of the surface roughness and its microstructure. The road width is directly related to the material feed rate and is adjusted with the existing firmware installed in the original control box. The road width is determined by measuring the wall thickness of the calibration target. This thickness is also predetermined by the diameter of nozzle $(0.4 \mathrm{~mm})$ being used, as shown in Table 2 . The road width may need to be performed several times until the system is properly calibrated. In this research, the ultrasonic actuator will be vibrated by ultrasonic power supply, with $20 \mathrm{kHz}$ and amplitude of $10 \mu \mathrm{m}$ which is the standard frequency [10].

Table 2: FDM Deposition Parameter

\begin{tabular}{|l|l|}
\hline \multicolumn{1}{|c|}{ Parameter } & \multicolumn{1}{|c|}{ Value } \\
\hline Road width, W & $0.76 \mathrm{~mm}$ \\
\hline Layer thickness, $\mathrm{t}$ & $0.25 \mathrm{~mm}$ \\
\hline Frequency & $20 \mathrm{kHz}$ \\
\hline
\end{tabular}

\section{Summary}

This research aims to present a new approach of ultrasonic-assisted FDM process to improve surface finish of FDM parts and considering the process parameter of layer thickness, road width and the speed of build. It extends the existing work by discussing the three experimental setup of ultrasound technology to improve the surface finish of parts produced from a desktop FDM system. A comparative study was made and an analysis is summarized in Table 1. Concept 1 has the most radical feature whereby the ultrasonic transducer is integrated with the heating block and the nozzle. Although this would avoid disturbing the process of melting the filament directly into nozzle, the main concern is that the heater block has a high temperature and could damage the transducer. Concept 2 is a variation of the first concept where the transducer is kept separate from the heater block and nozzle using a welded or screen sheet metal. This will prevent the dissipating heat from damaging the transducer and is seen as the safest approach and most feasible among all three concepts. Concept 3 suggests that the work piece is clamped on the surface of ultrasonic transducer. However, there is concern that the build process may be affected due to the vibration of the work piece. The second experimental setup (Concept 2) was found to be the most suitable due to its safety and reliability aspects. In order to validate the findings, the second concept will be studied in greater depth as the next phase to ascertain the technical advantages and disadvantages. Process parameters such as layer thickness, build density and the speed of build will be varied and will be investigated, along with material removal rate, accuracy, and the quality of surface finish. It is expected from this study that an ultrasonic-assisted FDM process has the potential to achieve better surface finish of parts produced. 


\section{Acknowledgements}

The authors would like to thank Universiti Teknikal Malaysia Melaka (UTeM) for their financial support, technical advice and suggestions.

\section{References}

[1] Galantucci, L. M., Lavecchia, F., \& Percoco, G. 2010. Quantitative Analysis of a Chemical Treatment to Reduce Roughness of Parts Fabricated Using Fused Deposition Modeling. CIRP Annals-manufacturing technology, 59(1), pp. 247-250.

[2] Croccolo, D., De Agostinis, M., \& Olmi, G. 2013. Experimental Characterization and Analytical Modeling of the Mechanical Behavior of Fused Deposition Processed Parts Made of ABS-M30. Computational Materials Science, 79, pp. 506-518.

[3] Sood, A. K., Ohdar, R. K., \& Mahapatra, S. S. 2012. Experimental Investigation And Empirical Modeling of FDM Process for Compressive Strength Improvement. Journal of Advanced Research, 3(1), pp. 81-90.

[4] Yang, J. J., Zhang, H., Deng, X. Z., \& Wei, B. Y. 2013. Ultrasonic Lapping of Hypoid Gear: System Design and Experiments. Mechanism And Machine Theory,65, pp. 71-78.

[5] Kim, W. J., Lu, F., Cho, S. H., Park, J. K., \& Lee, M. G. 2011. Design and Optimization of Ultrasonic Vibration Mechanism using PZT for Precision Laser Machining. Physics Procedia, 19, pp. 258-264.

[6] Jain, P., \& Kuthe, A. M. 2013. Feasibility Study of Manufacturing Using Rapid Prototyping: FDM Approach. Procedia Engineering, 63,pp. 4-11.

[7] Galantucci, L. M., Lavecchia, F., \& Percoco, G. 2009. Experimental Study Aiming to Enhance the Surface Finish of Fused Deposition Modeled Parts. CIRP Annals-Manufacturing Technology, 58(1), pp. 189-192.

[8] Ahn, D., Kweon, J. H., Kwon, S., Song, J., \& Lee, S. 2009. Representation of Surface Roughness in Fused Deposition Modeling. Journal of Materials Processing Technology, 209(15), pp. 5593-5600.

[9] Maidin, S., Abdul Aziz, K. F. \& Muhamad, M. K., 2014. Analysis of Applying Ultrasonic System on FDM Nozzle Using ANSYS. International Conference on Design and Concurrent Engineering $3^{\text {rd }}$ iDECON, 22-23 September 2014.

[10] Tabatabaei, S. M. K., Behbahani, S., \& Mirian, S. M. 2013. Analysis of Ultrasonic Assisted Machining (UAM) On Regenerative Chatter in Turning. Journal of Materials Processing Technology, 213(3), pp. 418-425. 